\title{
EXPLORING COMMUNICATIVE GESTURES IN CZECH PERSONS WITH DIAGNOSED APHASIA
}

\author{
MARTIN JANEČKA \\ Charles University in Prague, Prague, Czech Republic \\ martin.janecka@pedf.cuni.cz
}

\begin{abstract}
In my investigation, I worked with 6 persons with diagnosed aphasia. I introduce some possible perspectives on the exploration of the extent of speech damage in persons with aphasia and the various ways in which they substitute for language deficiency with the aid of gestures.

From the viewpoint of data processing methods, on the one hand, I explore the parameters of spoken language, such as the quantity of words, and, on the other hand, the parameters of gestures, such as the quantity of gestures, diversity of gestures, etc. In aphasic persons speaking Czech, I verify the following assumption established by Jakob et al. (2011): the more speech-limited an aphasic person is, the more gestures he/she produces during the interpretation of a story.

It was found that the number of words produced by aphasic persons varies, partially dependent on the specific type of aphasia. This is particularly true on both ends of the scale - people with large speech distortion use the highest quantity of gestures, people with low speech distortion use gestures to a lesser extent. Within the classification of semantic gestures, I focus particularly on iconic and deictic gestures. In addition, I presume that symbolic gestures (i.e. emblems) do not occur in aphasic persons' speech, because aphasic persons prefer gestures that display the plot in the most concrete way.

My data correlate with other studies dealing with this topic - aphasic persons do use gestures intentionally to substitute for their verbal deficiency. At the same time, they mostly use very concrete (iconic) gestures, which enable them to transmit a large volume of information.
\end{abstract}

Keywords: Aphasia, gestures, speech, nonverbal communication, multimodality

\section{Introduction}

Following the idea of multimodality (e.g. Kress, 2010), it is obvious that we should describe language according to the fact that non-verbal communication is accompanied by verbal language in the process of communication. ${ }^{1}$ As Alwood

\footnotetext{
${ }^{1}$ The idea of examining spoken language together with gestures has been developed since the 1970s, see e.g. Birdwhistell's (1970) famous book Kinesics and Context. Essays on Body Motion Communication, and, even earlier, Birdwhistell's mentor, Pike (1967).
} 
(2009: 210) claims, the basic reason for gathering multimodal corpora is that they afford material for more complex enquiries of the construction of meaning and understanding. Such enquiries are not fully practicable in corpora that contain linguistic material of a less comprehensive form, because much of the construction of information is implemented multimodally through a relationship of gestures and speech. Examples of multimodal corpora are digitised collections of texts illustrated with pictures and diagrams, or digitised collections of films connected with transcriptions of the dialogue in the films (Alwood, 2009: 207).

It is possible to mention e.g. Miller and Quek's (2011: 244) viewpoint, which is that the researcher works with specific examples of behaviour in the data and is able to examine the original video/audio recording of the behaviour. It allows the user to explore these instances within their contexts to decide whether recurring patterns are relevant to the examined behaviour. Then it is possible to say that multimodal corpora are both the most advantageous and the most adequate resource of material for such kinds of procedures - more can be seen in The Routledge Handbook of Multimodal Analysis (Jewitt et al., 2009/2016) and Multimodal Corpora (Kipp et al., 2009).

In my research including 6 Czech participants with different types of aphasia, I follow the assumption of Jakob et. al. (2011): The more speech-restricted an aphasic patient is, the more gestures he/she produces during the interpretation of a text. My data evince whether patients producing long or complex phrases use fewer gestures than patients producing short and less complex phrases; therefore, I explore the relationship between the rate of words matched to a gesture and the complexity of a phrase. Within gesture classification, I focus more on deictic and iconic gestures. The reason is that participants with aphasia within my research sample do not use symbolic gestures at all. The main reason for carrying out this research is the verification of the relationship between speech distortion and the production of gestures in Czech aphasic persons, which has never been explored to date.

Different types of aphasia (and this impairment in general) are introduced in section 1.1. Then, in chapter 2, the theoretical background follows, chapter 3 contains a description of the methods used and data description of my participants, chapter 4 contains the results of my observations and chapter 5 follows with a discussion of the results obtained and a comparison of my results with previous research. Chapter 6 is conclusion.

\subsection{Aphasia}

Aphasia can be defined as a language disorder that results from damage to a specific area of the brain involved in language processing. There are two main disorders - namely language production and language comprehension. The core of aphasic disability is concretely manifested in issues with grammar, lexicon, and semantics, in all areas of production or perception - speaking, listening, reading, 
and writing, etc. Kertesz (1979, cited from Teasell, 2016: 6) describes aphasia clinically as a neurologically central disorder of language, characterised by paraphasia, word finding difficulties and variably impaired comprehension, associated with a disorder of reading and writing, sometimes with dysarthria and a disability in the production of gestures. Persson (1995: 68) describes aphasia as "reduced capacity to organise linguistic items into patterns, a natural corollary of pathological language change in the items and/or relations among these items". She emphasises the fact that it is very difficult to find generally accepted criteria for distinguishing storage deficits from access deficits by participants with different kinds of aphasia.

The causes of aphasia are, in particular, cerebrovascular accidents (CVAs, commonly known as strokes) or various forms of haemorrhage. The other causes of aphasia may be various kinds of cerebral tumour, brain disease, or traumatic damage (Crystal, 2010: 280). In general, comprehension can be improved more rapidly than production. However, it is important to mention that these improvements are often only partial.

There are various classifications of aphasia, based on different criteria. The most widely known is probably the Boston classification of aphasia (see Table 1 below). Two main types of aphasia are Broca's and Wernicke's aphasia. It is important to mention that a change in aphasic symptoms might occur in the process of recovery and that aphasic symptoms are also often combined to a certain extent, so that a totally clear diagnosis is often not possible.

Considering Broca's aphasia, language is usually described as markedly nonfluent - slow, laboured, with great difficulty in articulation. Sentences are usually very short, with limited usage of grammatical constructions. Comprehension is relatively intact. However, Broca's aphasics often repeat individual words (usually non-semantic words e.g. particles) and omit grammatical words (e.g. reflexive clitics or word-forming morphemes, etc.).

In Wernicke's aphasia, language is usually described as (excessively) fluent, with almost no articulatory difficulty, but containing many neologisms and with a significantly chaotic speech structure in general. There may be unexpected pauses as well. The speech also illustrates different errors in choosing words and phonemes, as well as problems in retrieving lexical items from memory (see Crystal, 2010: 281).

Persons with transcortical-motor aphasia often have considerably restricted speech production and relatively intact comprehension. This is the opposite situation in transcortical-sensory aphasia.

Recent research by Preisig (2018: 9), using VLSM (voxel-based lesionsymptom mapping) demonstrates that participants with aphasia who produced more meaningful gestures significantly more often evinced a brain lesion involving the anterior part of the brain. Preisig (2018: 10) also describes how patients with lesions usually express heterogeneous symptoms, depending on the exact location of the lesion. Findings acquired from diffusion-tensor imaging 
show that the complexity of the structure of the white matter tract may influence the heterogeneity of the symptoms arising from its lesion.

Table 1. Boston classification of aphasia (see e.g. Teasell, 2016: 20)

\begin{tabular}{ccccc}
\hline Aphasia type & Fluency & Comprehension & Repetition & Naming \\
\hline $\begin{array}{c}\text { Broca's } \\
\text { aphasia }\end{array}$ & non-fluent & impaired & relatively intact & impaired \\
$\begin{array}{c}\text { Transcortical } \\
\text { motor aphasia }\end{array}$ & non-fluent & intact & relatively intact & impaired \\
$\begin{array}{c}\text { Wernicke's } \\
\text { aphasia }\end{array}$ & fluent & impaired & impaired & impaired \\
$\begin{array}{c}\text { Conduction } \\
\text { aphasia }\end{array}$ & fluent & impaired & relatively intact & impaired \\
$\begin{array}{c}\text { Transcortical } \\
\text { sensory } \\
\text { aphasia }\end{array}$ & fluent & intact & impaired & impaired \\
$\begin{array}{c}\text { Global } \\
\text { aphasia }\end{array}$ & impaired & impaired & impaired & impaired \\
\hline
\end{tabular}

\section{Theoretical background}

After defining aphasia as a language impairment and after the determination of different kinds of aphasia, I concentrate on research, including investigation of the verbal characteristics of people with aphasia, as well as their ability to use gestures. There are several options available for observing the connection between gestures and spoken language in persons with aphasia.

De Ruiter et al. (2012: 233) claim that there is a trade-off relationship between gestures and spoken language in terms of their communicative efficiency. The trade-off hypothesis presumes that if expressions in spoken language become more difficult, the probability of a gesture occurring is higher, taking over a part of the communication. Based on empirical evidence, they also claim that, similarly, when the use of gestures becomes more difficult, the trade-off hypothesis presumes that speakers depend more on speech.

The hand-in-hand hypothesis described by So et al. (2009: 5) contradicts the previous hypothesis: they claim that gestures go hand-in-hand with speech, targeting the significant parts of communication only when speech does, and vice versa. De Ruiter et al. (2012: 233) explore the connection between gesture and spoken language in situations where people refer to something in a shared visual environment. They investigate two types of gesture that are often produced when referring, and closely synchronised with affiliated speech: (a) pointing (or deictic) 
gestures and (b) iconic gestures. At the conclusion of their study, de Ruiter et al. (2012: 244) evaluate the trade-off and hand-in-hand hypotheses. Only one result is plausibly explained by the trade-off hypothesis: The rate of pointing decreases when directors repeat a referring expression.

In addition, de Ruiter et al. found evidence supporting the hand-in-hand hypothesis: The rate of pointing gestures is positively related to the quantity of locative descriptions in spoken language, and the rate of iconic gestures with the number of feature descriptions in spoken language. This indicates that, if standard speakers are used in the investigation, the hand-in-hand hypothesis is more relevant, while there may be a trade-off with non-standard speakers (children or people with a cognitive restriction). This is compatible with the results in de Ruiter, 2006 (see also So et al., 2009).

De Beer et al. (2017: 487) explored the differential effect of various gesture types on the comprehensibility of expressions by persons with aphasia, with the aid of a listener experiment (similarly to Hogrefe et al., 2013). They concentrated on gestures performed in spontaneous conversation to ensure the validity of their findings. This study (de Beer et al., 2017: 488) attempts to answer two basic questions: 1. Does gesture production increase communicative effectiveness for persons with aphasia presenting with a primary production deficit across a continuum of severity? 2. Which gesture types maintain the highest potential to add information to the language message?

De Beer et al. (2017: 494) found that the production of gestures by persons with aphasia had a serious impact on the comprehensibility of the aphasics' communication. These findings conduce to the communicative value of gestures for persons with aphasia. Results of their research support the view that a certain part of the information that persons with aphasia cannot express via spoken language is produced through gestures, because this modality remains partially intact. Listeners also confirm that, when a spoken discourse is difficult to decode, it is also difficult to interpret the meaning of a gesture, although information is more understandable when gestures are visible.

Although the information conveyed by a gesture can supplement the information conveyed in speech, there are situations in which gesture and speech convey information that appears to be redundant: for example, when gestures contribute information that is already fully expressed by spoken language (Abner, Cooperrider and Goldin-Meadow, 2015: 442). We presume that speakers produce their gestures primarily to disambiguate ambiguities in their spoken expressions (see de Ruiter, Bangerter, and Dings, 2012: 238).

For purposes of this paper, I verify the following assumption, which was established by Jakob et al. (2011): The more speech-limited a person with aphasia is, the more gestures he/she produces when retelling a story.

There are also two secondary assumptions exploring whether a) persons with aphasia producing long or complex phrases produce fewer gestures than persons with aphasia producing short and less complex phrases, and whether b) persons 
with aphasia with lower lexical diversity produce more gestures than persons with aphasia with higher lexical diversity. In other words, the connections between the rate of words connected to a gesture and the length of a phrase were explored.

Jakob et. al (2011) compared 10 participants with aphasia and 10 participants without visible language distortion. They conclude that participants with aphasia produce more gestures than people without aphasia, and participants with aphasia also produce more different types of gestures and more complex gestures, i.e. gesture movements are held for a longer time period and more often consist of several small gestures. A disadvantage of their study is the fact that it is not obvious which types of aphasia were included in their research sample.

It is also appropriate to mention the research of Wiesmayer et al. (2011). They included 8 participants in their research: 3 with amnesic aphasia, 3 Broca's, and 2 Wernicke's aphasia. The results were the same for each participant, regardless of the type of aphasia suffered, but they conclude that the severity of aphasia has no significant influence on gesture production within their research sample.

Another branch of research investigating the relationship between speech and non-verbal activity in aphasic persons emphasises the importance of semantic cognition. According to Corbet et al. $(2009,2594)$, semantic cognition refers to the processes and representations that underlie our understanding and use of the meanings of words, pictures, objects, sounds, etc. (Jeffries et al., 2008; Jefferies and Ralph, 2006). It plays an important role in many common activities, not only in the verbal area (for the transmission of meaning between the source and recipient), but also in a set of non-verbal activities. Thus, impairments of semantic cognition are highly debilitating and can arise in different disorders, including semantic dementia (SD) and in some patients with semantic aphasia (SA). The qualitative nature of the impairment, however, is dependent on which constituent of semantic cognition is influenced in a particular group of patients.

My research does not concentrate on non-verbal abilities related to semantic aphasia in the sense of e.g. Corbett et al. (2009). Among the non-verbal abilities, they judge a patient's ability to select the typical recipients of tools, their ability to select objects with related functions, even though these tasks involve the same items, using pictures as stimuli with required pointing response, etc. I resolve the aforementioned areas of interest in other studies (Janečka, 2021; Janečka, in print), taking into account many more research viewpoints, e.g. semantic paraphasia, which covers the area of semantic cognition damage.

Corbet et al. (2009: 2607) also mention apraxia as an important factor in this kind of research. They describe apraxia as "an impaired ability to use everyday objects due to a deficit at the level of conceptual knowledge, either due to a lack of access to the semantic store or through disturbance of the sequential organisation of actions." Apraxia has previously been referred to as "ideational apraxia" (IA) and has been related to temporoparietal lesions, i.e. an important region of damage in SA cases. Two participants included in my research, Mtm and $\mathrm{Mb}$ 2, suffer from right-hand apraxia, but their only restriction is that they 
produce gestures only with the left hand. Nevertheless, their gestures are not less concrete than other participants' gestures. It is obvious that persons with serious apraxia would not be suitable for this kind of research.

\section{Methods}

Within my investigation, I create a database of video recordings of aphasic people and healthy control persons. I compare how these two groups differ, when considering the quantity and types of gestures produced regarding their language production. I do not describe paralinguistic phenomena such as laughter, intonation, pauses, etc. I am aware of the fact that facial expressions under specific circumstances can convey or modify information, but I restrict my investigation only to the field of gestures. In this article, I work only with persons with aphasia. ${ }^{2}$

Every aphasic person participating in my research watched the cartoon Shaun the Sheep for a duration of approximately 24 minutes. The subsequent conversation was related to this movie and the procedure was always carried out in the following way: 1) At first, the person retells the story, i.e. everything he/she is capable of remembering; 2) After completion of the monologue (with no interventions and with only minimal prompting, such as "What happens next?" or "What else?"), the person answers questions, such as "What are the individual characters in this film like?" or "What does a particular part of the film symbolise?" etc.

\subsection{Gesture classification}

Within the exploration of data, I work with two basic groups of gestures: gestures with communicative function and gestures with non-communicative function, based on Hogrefe (2009) or Hogrefe et al. (2013). Jokinen et al. (2009) also describe the first group of gestures as gestures with communicative function. A comparison to other important gesture classifications lies beyond this differentiation, e.g. McNeill (1992), his emblems, deictic, iconic and metaphoric gestures belong to communicative gestures, beats to non-communicative gestures, and pantomime as complex, sequential movements. Communicative gestures include, in particular, movement of the hands extending outwards from the body, head movements (e.g. nodding), and shoulder movements (e.g. shrugging). Gestures with non-communicative function include e.g. touching oneself, i.e. gestures only with an auto-stimulative function.

Gesture form is described in terms of the parameters used to describe sign languages - the shape and placement of the hand, trajectory of the motion. A

\footnotetext{
2 These persons were addressed by the non-profit organisation Club Aphasia in Prague, where secondary therapy for aphasic people is provided. There were no additional criteria for participation in this investigation, i.e. all who were interested in participation were accepted.
} 
change in any of these parameters marks the end of one gesture and the beginning of another as well. Each gesture was assigned a meaning, indicating what was represented in the gesture (see So et al., 2009: 4).

As a basic typology of gestures, I take over the classification by Hogrefe (2009), where the group of gestures for transmitting a meaning is called semantic gestures. Three large subgroups of semantic gestures are pictographs, deictic gestures and emblems. In the wide group of pictographs, which can illustrate various objects, on the one hand are iconographs (object drawing in the space), and on the other hand, kinetographs, which can represent the manner or speed of a movement. Another independent group of gestures is deictic gestures. We can further differentiate between concrete deictic gestures, which are used to point out a specific object in space, and abstract deixis in a situation when one points out the empty space in front of the body in describing an imaginary situation. The last group of semantic gestures is emblems, i.e. symbolic gestures that are specialised formally and in meaning. This meaning is conditioned by culture and language, e.g. two fingers forming a $V$ as the symbol for "victory" or when giving a salute.

For the purposes of this article, I decided to delimit one large group of semantic gestures (pictographs, deictics and emblems together) and processual gestures (or sometimes called metaphoric, e.g. McNeill, 1992), where the meaning is not so clear, but these gestures are often related to non-semantic verbs (verbs with low semantics, sometimes called light verbs, e.g. work, think, process, etc.). In the final chapter, when summarising the verifications of Jakob's assumptions, I count them all as communicative gestures, as opposed to non-communicative gestures, i.e. only with auto-stimulative functions. Even if they can signal something emotive, they are not able to substitute for lexical expression.

With reference to the classification of individual gestures into the categories described above, it is necessary to mention that there always was a requisite agreement by at least two out of three annotators (the author of this article and two trained student assistants), so the condition of inter-rater reliability should be guaranteed. At least $84 \%$ of gestures were classified in the same way by all three annotators in all persons with diagnosed aphasia. ${ }^{3}$

\subsection{Data description}

Six persons with aphasia were involved in this investigation. In Table 2, the description of persons with aphasia includes information of age, gender, aetiology, education, aphasia duration, and type of aphasia. Persons with aphasia were recorded for the average time of 23 minutes. Mw1, a male with Wernicke's aphasia, was in a very bad psychological mood during the video recording, so that the whole examination process had to be ended sooner than in the other cases. A

\footnotetext{
${ }^{3}$ To be more specific, we reached an agreement on $88.9 \%$ of gestures by Mtm, $84.6 \%$ of gestures by Wtm, $87 \%$ of gestures by Mw1, $89.8 \%$ of gestures by Mb2, $88.3 \%$ of gestures by Mw2 and $91.5 \%$ of gestures by Mb1.
} 
similar situation arose with $\mathrm{Ztm}$, a female with transcortical-motor aphasia, but it was not necessary to stop the recording immediately in her case. Thus, we can say that not only the degree of seriousness of aphasia, but also the actual psychological mood are important in these studies.

The explored data are connected with demographic and clinical data (sex, age, years of education, highest achieved degree of education, occupation, type and seriousness of aphasia within the clinical group based on the Bostonian classification of aphasia, time of origin of the disorder and its aetiology, including the localisation of the lesion). The data are anonymised, and individual participants are identified with the aid of alphanumerical codes.

Persons included in my research are members of Club Aphasia, a non-profit organisation in Prague. Clients of this organisation were addressed by a Speech Therapist in a collective session. Those who had an interest were addressed by me afterwards. Every participant was asked to sign an ethical statement that his/her involvement within this research is voluntary and that he/she may cancel this participation at any time and can also make a request for the deletion of his/her data from my database.

Descriptions of my participants are as follows: Mtm: male with transcorticalmotor aphasia; Wtm: female with transcortical-motor aphasia; Mb1 and Mb2: males with Broca's aphasia; Mw1 and Mw2: males with Wernicke's aphasia. I am aware of the fact that the examined group is not gender-balanced. The reason is that it is much easier to find men than women who are willing to participate in this type of research.

Table 2. Description of persons with aphasia

\begin{tabular}{ccccccc}
\hline Person & Gender & Age & Education & $\begin{array}{c}\text { Aphasia } \\
\text { duration }\end{array}$ & $\begin{array}{c}\text { Aetiology } \\
\text { and lesion }\end{array}$ & $\begin{array}{c}\text { Type of } \\
\text { aphasia }\end{array}$ \\
\hline $\mathrm{Mb} 1$ & male & 69 & college & 9 years & $\begin{array}{c}\text { iCMP(ACM } \\
\text { sin.),central }\end{array}$ & Broca \\
$\mathrm{Mb} 2$ & male & 67 & $\begin{array}{c}\text { high } \\
\text { school }\end{array}$ & 20 years & hCMP & Broca \\
Wtm & female & 56 & $\begin{array}{c}\text { vocational } \\
\text { school }\end{array}$ & 3 years & $\begin{array}{c}\text { iCMP(ACM } \\
\text { sin),FTP }\end{array}$ & $\begin{array}{c}\text { Transcortical } \\
\text { motor }\end{array}$ \\
Mw2 & male & 79 & college & 3 years & iCMP, TP & $\begin{array}{c}\text { Wernicke } \\
\text { (conduction) }\end{array}$
\end{tabular}




\begin{tabular}{|c|c|c|c|c|c|c|}
\hline $\mathrm{Mtm}$ & male & 46 & college & $\begin{array}{l}5 \text { years } \\
6 \text { months }\end{array}$ & $\begin{array}{c}\text { iCMP(ACA, ACM } \\
\sin )\end{array}$ & $\begin{array}{c}\text { Transcortical } \\
\text { motor }\end{array}$ \\
\hline Mw1 & male & 71 & $\begin{array}{c}\text { vocational } \\
\text { school }\end{array}$ & $\begin{array}{l}3 \text { years } \\
7 \text { months }\end{array}$ & hCMP,T & Wernicke \\
\hline
\end{tabular}

List of aetiologies: $\mathrm{iCMP}=$ ischemic cerebrovascular accident, $\mathrm{ACM}$ sin. $=$ arteria cerebri media, hCMP $=$ hemorrhagic cerebrovascular accident, FTP $=$ frontotemporoparietal, $\mathrm{TP}=$ temporoparietal, $\mathrm{ACA}=$ arteria cerebri anterior, $\mathrm{T}=$ temporal.

\section{Results}

Table 3. Communicative gestures to words in total ratio

\begin{tabular}{ccccccc}
\hline Person & $\begin{array}{c}\text { Type of } \\
\text { aphasia }\end{array}$ & Words & $\begin{array}{c}\text { Semantic } \\
\text { gestures }\end{array}$ & $\begin{array}{c}\text { Processual } \\
\text { gestures }\end{array}$ & $\begin{array}{c}\text { Communicative } \\
\text { gestures in total }\end{array}$ & $\begin{array}{c}\text { Individual } \\
\text { gestures to } \\
\text { words ratio } \\
(\%)\end{array}$ \\
\hline Mtm & $\begin{array}{c}\text { Transcortical } \\
\text { motor }\end{array}$ & 1085 & 24 & 16 & 40 & 3.69 \\
Wtm & $\begin{array}{c}\text { Transcortical } \\
\text { motor }\end{array}$ & 823 & 22 & 0 & 22 & 2.67 \\
Mw1 & $\begin{array}{c}\text { Wernicke } \\
\text { Mb2 }\end{array}$ & 757 & 10 & 9 & 19 & 2.51 \\
Mw2 & Broca & 752 & 52 & 1 & 53 & 7.05 \\
Wernicke & 591 & 62 & 6 & 68 & 11.51 \\
\hline (conduction) & Broca & 582 & 119 & 0 & 119 & 20.45 \\
\hline
\end{tabular}

Following the research of Jakob et al. (2011), the number of words used in interpreting a story is the measure of speech impairment. I do not consider the effectiveness in telling a story, as was done e.g. by Bartmann et al. (2011).

Person Wtm is diagnosed with transcortical-motor aphasia. She produced 823 words in total. She produced 22 semantic gestures, of which 11 gestures were used

4 Ratio in the table means that e.g. Mb1 used an individual communicative gesture during $20.45 \%$ of his speech etc. 
in conjunction with the word of the same meaning and 8 gestures with a word of a different meaning (see Table 3.). It is notable that she used neither processual nor non-semantic gestures in conjunction with words - and neither did she use processual nor non-semantic gestures expressed without words. She used 3 semantic gestures without words, with 1 gesture being related to the following word and 2 gestures which completely replaced words. In this case, it is also possible that psychological factors could have played a role - she was quite nervous, and whenever she finally used a gesture, she was very focused on producing only a very specific one.

Despite the relatively short recorded test time, the recording of the person Mw1 contains 757 words, which corresponds with the fact that the speech of Wernicke's aphasics is relatively fluent, but contains many neologisms ${ }^{5}$ and has a significantly chaotic structure of verbal expression in general, as described e.g. in Crystal (2010: 281). Similar results are to be found in Hogrefe et al. (2013: 7): all participants with Wernicke's aphasia (5 of 16 participants) evinced the same types of manifestation as seen in my research sample. Kong et al. (2015: 92) are also in agreement with these findings, when describing the fact that speakers with Wernicke's aphasia use gestures that are more abstract, such as metaphoric or referential gestures. It is appropriate to mention that Preisig's (2018) research involved 3 participants with Wernicke's aphasia (out of a total of 20 participants), but there was no visible dependency in the measured values.

Person Mw1 did not produce gestures to substitute for his language deficiency. With regard to the fact that this person always only used co-speech gestures (i.e. gestures produced simultaneously with words), their more detailed classification is as follows: person Mw1 produced 10 semantic gestures and 9 processual gestures, of which 8 were semantic gestures with the given word and only 2 with another word; with reference to processual gestures, there were also 8 gestures with the given word and only 1 gesture with another word (see Table 3.).

There are two possible factors that could have influenced the very low frequency of gestures in his utterance: 1) the number of words (757 words during approx. 18 minutes) and together with this fact corresponding to Mw1's assumption that he is able to transmit a significant amount of information ${ }^{6}$ without the necessity of utilising gestures; 2) the fact that this person was very nervous (similarly to $\mathrm{Wtm}$ ), not very co-operative, and not relaxed during the entire time of the recording process, which also might have influenced the less noticeable production of non-verbal expressions.

Regarding very limited speech fluency, the person Mb1 expressed only 582 words. Considering his speech limitation, he produced only semantic gestures (119) - he did not use any processual gestures (but a quite high quantity of non-

5 A new word, but with no sense - the sequential order of phonemes is often changed.

6 His utterance was often unintelligible, but he was not aware of this. This is often symptomatic in people with Wernicke's aphasia. 
semantic gestures). It was anticipated that he would use more gestures without spoken accompaniment, nevertheless, he produced only 10 .

Person Mb1 used 109 semantic gestures during his storytelling: 23 of them were expressed by a word carrying the meaning corresponding to an implemented gesture and 86 gestures were produced in instances other than when the intended meaning was expressed by words (see Table 3.). This could relate to the fact that person Mb1 was able to represent very concrete (mostly iconic) gestures that enabled him to remember individual words (or even phrases), which he was able to express afterwards - this is concordant with regard to the interface approach (So et al., 2009: 2). For detailed data of the other 3 participants, see Table 3.

The persons with aphasia included in my research produced a relatively high quantity of gestures during text reproduction. Regarding the number of uttered words, 3 out of the 6 participants with aphasia produced more communicative gestures than the other 3 aphasic participants. To be more precise, the most speech-limited person's (Mb2) ratio is $20.45 \%$ communicative gestures to words. Thereafter, the dependency continues, because the second most speech-limited person's (Mw2) ratio is $11.51 \%$, followed by Mb2 at $7.05 \%$, followed by the rest of the participants with aphasia (Mtm, Wtm and $\mathrm{Mw} 1$, the ratio is between 2.51 $\%$ and $3.69 \%$, see Table 3 ).

Table 4. Words influenced by communicative gestures to words in total ratio

\begin{tabular}{ccccc}
\hline Person & Words & $\begin{array}{c}\text { Words } \\
\text { influenced by } \\
\text { semantic } \\
\text { gestures }\end{array}$ & $\begin{array}{c}\text { Words } \\
\text { influenced by } \\
\text { processual } \\
\text { gestures }\end{array}$ & $\begin{array}{c}\text { Words influenced by } \\
\text { communicative gestures to } \\
\text { words ratio (\%) }\end{array}$ \\
\hline $\mathrm{Mtm}$ & 1085 & 61 & 23 & 7.74 \\
$\mathrm{Wtm}$ & 823 & 28 & 0 & 3.4 \\
$\mathrm{Mw1}$ & 757 & 18 & 12 & 3.96 \\
$\mathrm{Mb} 2$ & 752 & 52 & 1 & 7.05 \\
$\mathrm{Mw} 2$ & 591 & 84 & 6 & 15.23 \\
$\mathrm{Mb} 1$ & 582 & 222 & 0 & 38.14 \\
\hline
\end{tabular}

Considering the rate of words matched to a communicative gesture by persons with aphasia, 2 of the aphasic persons evinced a notably higher ratio of words influenced by communicative gestures to words in total than the remaining aphasic persons. To be more precise, $38.14 \%$ of Mb1's storytelling is influenced by communicative gestures. In 2 nd place, there is Mw2 at $15.23 \%$. The third 
participant with aphasia shows a ratio of $7.74 \%(\mathrm{Mtm})$ and the fourth (Mb2) shows a ratio of $7.05 \%$. For further details see Table 4 .

Ratio in the table means that e.g. $38.14 \%$ of Mb1's speech was accompanied by a gesture form. The obvious difference between ratios in Table 3 and Table 4 consists of the fact that 1 gesture can cover up to 5 words.

Table 5. Concrete and abstract deictic gestures

\begin{tabular}{cccccccc}
\hline Person & $\begin{array}{c}\text { Type of } \\
\text { aphasia }\end{array}$ & Words & $\begin{array}{c}\text { Communicative } \\
\text { gestures }\end{array}$ & $\begin{array}{c}\text { Deictics } \\
\text { in total }\end{array}$ & $\begin{array}{c}\text { Concrete } \\
\text { deictics }\end{array}$ & $\begin{array}{c}\text { Abstract } \\
\text { deictics }\end{array}$ & $\begin{array}{c}\text { Iconic } \\
\text { gestures }\end{array}$ \\
\hline Mtm & $\begin{array}{c}\text { Transcortical } \\
\text { motor }\end{array}$ & 1085 & 40 & 10 & 6 & 4 & 30 \\
Wtm & $\begin{array}{c}\text { Transcortical } \\
\text { motor }\end{array}$ & 823 & 22 & 8 & 3 & 5 & 14 \\
Mw1 & $\begin{array}{c}\text { Wernicke } \\
\text { Mb2 }\end{array}$ & 757 & 19 & 8 & 0 & 8 & 11 \\
Mw2 & $\begin{array}{c}\text { Bernicke } \\
\text { (conduction) }\end{array}$ & 752 & 53 & 18 & 7 & 11 & 35 \\
Mb1 & Broca & 582 & 119 & 15 & 6 & 8 & 56 \\
\hline
\end{tabular}

With reference to the aforementioned large group of semantic gestures, I focus more on deictic and iconic gestures. The reason why symbolic gestures (i.e. emblems) are not included is that the persons with aphasia did not use them at all. The exact numbers of abstract and concrete deictic gestures are to be found in Table 5. Further, I point out the overall patterns and specific findings of interest.

Person Mw2 very often helped himself when describing a certain situation. He also pointed to himself when describing his inability to speak and also reflected my presence in the recording, when he tried to involve me in the communication. He used deictics partially as pro-speech gestures (i.e. gestures produced in situations when they help to retrieve a word), partially as substitution for his spoken expression. His use of deictic gestures is very similar to person Mb1 - who also often used a very concrete deictic gesture, e.g. when pointing to the button on his trousers to express buttons (in the function of coins) appearing in one episode of the cartoon, Shaun the Sheep.

Person Wtm often pointed into empty space when thinking about what to say next, and a concrete deictic gesture was always present when counting (people, animals, hours, etc.). The same is valid for person Mtm. The relatively low quantity of gestures was probably connected with her significant nervousness. The 
very low rate of meaningful gestures of person Mw1 relates to the chaotic spoken expression of this Wernicke's aphasic and probably relates to his high level of nervousness as well.

Person Mb2, similarly to person Wtm, also often pointed into empty space when thinking about what to say next (or more precisely, how to say it), but meaningful gestures prevailed - particularly when counting something (people, animals, hours, etc.). He suffers from partial apraxia; thus, the relatively high number of gestures is quite surprising. He also used both pro-speech gestures (when trying to express something in spoken language) and co-speech gestures (to support his lexical expression).

\section{Discussion}

Primary observations evince that my data correlate with the data of Jakob et al. (2011). Nevertheless, I would be more certain of this after involving more persons with aphasia in my investigation.

It is possible to claim that there is an obvious connection of two facts: 3 aphasic persons produce more gestures to words than other aphasic persons, and a significant number of words by aphasic persons in the first three places is influenced by communicative gestures - thus, the first three places are the same in both indices.

I have verified the following hypothesis: the more speech-limited an aphasic person is, the more gestures he/she produces when retelling a story, i.e. the fewer words an aphasic person expresses, the more gestures he/she uses in his/her storytelling. My data evince that this is valid for almost all the observed aphasics, except Mtm, who used the highest number of words (1085) and, quite surprisingly, a high number of communicative gestures (40).

In general, aphasics use fewer deictics than persons without aphasia, because aphasic persons need to transmit information (semantics) with gestures and thus specifically choose iconic gestures. It is also necessary to mention that a lower occurrence of deictics was expected, because of the specific task of retelling a story: deictics are not so necessary when people are describing a very concrete story - but that does not mean that deictic gestures are not important in my research, they are just not as frequent as iconic gestures.

Deictics occur particularly as pro-speech gestures by persons with severe aphasia and as co-speech gestures by aphasics with relatively fluent speech. They may also occur in post-speech gestures, but I do not reflect this type of gesture within my investigation, because aphasics do not use them at all.

I would also point out a very interesting fact that aphasics do not need emblems (i.e. symbols in the terminology of semiotics) at all. It is not possible to determine the reasons for this without speculating. However, one thing is certain: they do not use emblems because they prefer being as iconic as possible. 
My data show that participants with Broca's aphasia have a tendency to produce fewer words (and mostly non-semantic words as pronouns) than participants with Wernicke's and transcortical-motor aphasia, which is substituted by quite a high quantity of communicative gestures. However, there is at least one exception, because person Mw2 inclines to Broca's symptoms considering the gestures' production: he produced the second highest number of gestures, which completely correlates with the second lowest number of words. A reason for this could be the fact that his comprehension is severely impaired, and he is not able to reflect the questioner's request (to retell a story). The question is whether he should not be excluded from the examined group for that reason. In the case of a higher number of examined persons, the aforementioned fact would be a possible reason for his exclusion. However, regarding the low number of examined persons willing to participate in this kind of research and regarding the fact that he was able to retell the story in some way, there is no essential reason for his exclusion.

It is also possible to claim that persons with more distorted speech produce all types of gestures, particularly as pro-speech gestures, and that co-speech gestures are used by participants with aphasia with relatively fluent speech.

Considering the hypothesis that persons with aphasia use more complex gestures than the healthy control people, it is necessary to make a more detailed classification of gestures, probably based on HamNoSys (Hamburg Sign Language Notation System), i.e. a set of components of non-verbal communication that can participate in the creation of meaning, consists of roughly 200 initial configurations of hands (shape and position of hands, localisation), together with a set of possibly integrated actions. In future research, special attention will be given to complex gestures and the interconnection among different gestures (meaning a transitional zone, see e.g. Mittelberg, 2018), because I am aware of the fact that in many cases it is not possible to definitively classify a gesture as a specific type of gesture. It is therefore necessary rather to consider a gesture scale.

\section{Conclusion}

It is necessary to mention that my results are only of an illustrative nature and demonstrate a first insight into the problematic in Czech linguistic aphasiology. During this research, it was necessary to annotate all the data manually. Considering the small extent of my data, the expected relationship between words produced and communicative gestures was not tested by advanced statistical tools. My study is only a pilot study, with the aim of pointing out a certain research direction.

Although only 6 Czech participants are involved in my research sample, it is obvious that there is a dependency between the severity (or a particular type) of aphasia and the quantity and type of used gestures. Both participants with 
transcortical-motor aphasia use a relatively low quantity of gestures. They can express most of their ideas in words, so they do not need to use gestures to support (or substitute for) their verbal deficiency.

Participants with Wernicke's aphasia are typical in their chaotic verbal expressions involving many neologisms (or words with modified phonemic order). It is interesting that, while one participant uses a relatively small number of gestures and it seems that he has no need to support his speech with gestures, the other participant, similarly to Broca's aphasic participants, uses a high quantity of gestures, also related to the efforts to help himself with gestures. Both Broca's participants are typical in the small number of words used and the high quantity of mostly iconic gestures made. Their efforts to support or even substitute their speech with gestures are significant.

It is also obvious that, even though the speech production of these participants with aphasia is restricted, their gesture production functions well or is only partially restricted due to apraxia.

\section{Acknowledgement}

The paper is written by a single author, who declares no conflict of interest. This research did not receive any specific grant from funding agencies in the public, commercial, or not-for-profit sector.

\section{References}

Abner, Natasha, Cooperrider, Kensy, and Goldin-Meadow, Susan. 2015. Gesture for Linguists: A Handy Primer. Language and Linguistics Compass, 9(11), 437-451. https://doi.org/10.1111/lnc3.12168

Alwood, Jens. 2009. Multimodal Corpora. In Lüdeling, A. and M. Kytö (eds), Corpus Linguistics. An International Handbook, 207-225. Berlin: Mouton de Gruyter.

Bartmann, D., Jakob, H., Ziegler, W. and G. Goldenberg. 2011. Zussamenhang von Spontansprachproduktion und Gesten bei Patienten mit Aphasie. Aphasie und verwandte Gebiete, 30(3), 5-19.

de Beer, C., Carragher, M., van Nispen, K., Hogrefe, K., de Ruiter, J. P. and M. L. Rose. 2017. How Much Information Do People With Aphasia Convey via Gesture? American journal of speechlanguage pathology, 26 (2), 483-497. https://doi.org/10.1044/2016 AJSLP-15-0027

Birdwhistell, Ray L. 1970. Kinesics and Context. Essays on Body Motion Communication. Philadelphia: University of Pennsylvania Press. https://doi.org/10.9783/9780812201284

Corbett, Faye, Jefferies, Elizabeth, Ehsan, Sheeba and Ralph, Mathew. A. Lambon. 2009. Different impairments of semantic cognition in semantic dementia and semantic aphasia: evidence from the non-verbal domain. Brain, 132, 2593-2608. https://doi.org/10.1093/brain/awp146

Crystal, David. 2010. The Cambridge encyclopedia of language. Cambridge: Cambridge University Press.

Hogrefe, Katharina, Ziegler, Wolfram, Wiesmayer, Susanne, Weidinger, Nicole. and Goldenberg, Georg. 2013. The actual and potential use of gestures for communication in aphasia. Aphasiology, 27(9), 1070-1089. https://doi.org/10.1080/02687038.2013.803515 
Hogrefe, Katharina. 2009. Aphasie, Apraxie und Gestik: Zur Produktion von Handgesten bei Patienten mit linkhemisphärischer Hirnschädigung. Dissertation, Universität Potsdam.

Jakob, Hanna, Bartmann, Daniela, Goldenberg, Georg, Ziegler, Wolfram and Hogrefe, Katharina. 2011. Zussamenhang von Spontansprachproduktion und Gesten bei Patienten mit Aphasie. Aphasie und verwandte Gebiete, 30(3), 20-38.

Janečka, Martin. In print. Gestikulace v komunikaci osob s diagnostikovanou afázií. Praha: Karolinum.

Janečka, Martin. 2021. The relationship between speech and gestures in persons with aphasia: Evidence from the Czech perspective. Topics in Linguistics, 22(1), 1-14. https://doi.org/10.2478/topling-2021-0001

Jefferies, Elizabeth., Patterson, Karalyn and Ralph, Mathew A. Lambon. 2008. Deficits of knowledge vs. executive control in semantic cognition: insights from cued naming. Neuropsychologia, 46(2), 649-658. https://doi.org/10.1016/j.neuropsychologia.2007.09.007

Jefferies, Elizabeth. and Ralph, Mathew A. Lambon. 2006. Semantic impairment in stroke aphasia versus semantic dementia: a case-series comparison. Brain, 129, 2132-2147. https://doi.org/10.1093/brain/awl153

Jewitt, Carey. (ed) 2009, 2016. The Routledge Handbook of Multimodal Analysis. London - New York: Routledge.

Jokinen, Kristiina, Navarretta, Costanza and Paggio, Patrizia. 2008. Distinguishing the Communicative Functions of Gestures: An Experiment with Annotated Gesture Data. In R. Stiefelhagen and A. Popescu-Belis (eds), MLMI 2008: Machine Learning for Multimodal Interaction, 38-49. https://doi.org/10.1007/978-3-540-85853-9_4

Kertesz, Andrew. 1979. Aphasia and associated disorder: Taxonomy, localization and recovery. New York: Grune \& Stratton, Inc.

Kipp, Michael, Martin, Jean-Claude., Paggio, Patrizia and Heylen, Dirk. 2009. Multimodal Corpora: From Models of Natural Interaction to Systems and Applications. Berlin - Heidelberg: Springer Verlag. https://doi.org/10.1007/978-3-642-04793-0

Kong, Anthony Pak-Hin, Law, Sam-Po, Wat, Watson Ka-Chun and Lai, Christy. 2015. Co-verbal gestures among speakers with aphasia: Influence of aphasia severity, linguistic and semantic skills, and hemiplegia on gesture employment in oral discourse. Journal of Communication Disorders, 56, 88-102. https://doi.org/10.1016/j.jcomdis.2015.06.007

Kress, Gunther. 2010. Multimodality: a social semiotic approach to contemporary communication. London: Routledge. https://doi.org/10.4324/9780203970034

McNeill, David. 1992. Hand and mind: What gestures reveal about thought. Chicago: University of Chicago Press.

Miller, Chreston and Quek, Francis. 2011. Toward Multimodal Situated Analysis. In J. Oncina (ed), Proceedings of the 13th international conference on multimodal interfaces, 239-246. New York: Association for Computing Machinery. https://doi.org/10.1145/2070481.2070526

Mittelberg, Irene. 2018. Gestures as image schemas and force gestalts: A dynamic systems approach augmented with motion-capture data analyses. Cognitive semiotics, 11(1), 1-21. https://doi.org/10.1515/cogsem-2018-0002

Persson, Inga Britt. 1995. Connectionism, Language Production and Adult Aphasia. Helsinki: The Finnish Society of Sciences and Letters. https://doi.org/10.1017/S0332586500004030

Pike, Kenneth Lee. 1967. Language in Relation to a Unified Theory of the Structure of Human Behaviour. The Hague: Mouton. https://doi.org/10.1515/9783111657158

Preisig, Basil C. 2018. Multimodal Communication in Aphasia: Perception and Production of Cospeech Gestures During Face-to-Face Conversation. Frontiers in Human Neuroscience, 12, article 200. https://doi.org/10.3389/fnhum.2018.00200

de Ruiter, Jan P., Bangerter, Adrian and Dings, Paula. 2012. The Interplay Between Gesture and Speech in the Production of Referring Expressions: Investigating the Trade-off Hypothesis. Topics in Cognitive Science, 4(2), 232-248. https://doi.org/10.1111/j.1756-8765.2012.01183.x 
de Ruiter, Jan P. 2006. Can gesticulation help aphasic people speak, or rather, communicate? Advances in Speech-Language Pathology, 8(2), 124-127. https://doi.org/10.1080/14417040600667285

So, Wing Chee, Kita, Sotaro and Goldin-Meadow, Susan. 2009. Using the Hands to Identify Who Does What to Whom: Gesture and Speech Go Hand-in-Hand. Cognitive Science, 33(1), 115125. https://doi.org/10.1111/j.1551-6709.2008.01006.x

Teasell, Robert. 2016. Aphasia and Apraxia. London, Ontario: Parkwood Institute.

Wiesmayer, Susanne, Hogrefe, Katharina, Ziegler, Woflram and Goldenberg, Georg. 2011. Sag es mit den Händen! Welches Potenzial bergen Gesten für die Kommunikationsfähigkeit aphasischer Sprecher? Aphasie und verwandte Gebiete, 30(3), 39-57. 